\title{
Insulin and Fibroblast Growth Factor 2 Activate a Neurogenic Program in Müller Glia of the Chicken Retina
}

\author{
Andy J. Fischer, Christopher Roger McGuire, Blair Dorian Dierks, and Thomas A. Reh \\ Department of Biological Structure, University of Washington, Seattle, Washington 98195
}

We have reported previously that neurotoxic damage to the chicken retina causes Müller glia to dedifferentiate, proliferate, express transcription factors common to retinal progenitors, and generate new neurons and glia, whereas the majority of newly produced cells remain undifferentiated (Fischer and Reh, 2001). Because damaged retinal cells have been shown to produce increased levels of insulin-related factors and FGFs, in the current study we tested whether intraocular injections of growth factors stimulate Müller glia to proliferate and produce new neurons. We injected growth factors and bromodeoxyuridine into the vitreous chamber of the eyes of chickens and assayed for changes in glial phenotype and proliferation within the retina. Although insulin or FGF2 alone had no effect, the combination of insulin and FGF2 caused Müller glia to coexpress transcription factors common to retinal progenitors (Pax6 and $\mathrm{Chx10)}$ and initiated a wave of proliferation in Müller cells that began at the retinal margin and spread into peripheral regions of the retina. Most of the newly formed cells remain undifferentiated, expressing Pax6 and Chx10, whereas some differentiate into Müller glia, and a few differentiate into neurons that express the neuronal markers Hu or calretinin. There was no evidence of retinal damage in eyes treated with insulin and FGF2. We conclude that the combination of insulin and FGF2 stimulated Müller glia to dedifferentiate, proliferate, and generate new neurons. These findings imply that exogenous growth factors might be used to stimulate endogenous glial cells to regenerate neurons in the CNS.

Key words: retina; insulin; FGF2; chick; Müller glia; regeneration; stem cell; progenitor
The potential for neural regeneration in the adult CNS of warmblooded vertebrates has increased in likelihood with the discovery of neural stem cells. Several studies have demonstrated that particular types of neurons can be regenerated in the cortex of mice (Magavi et al., 2000), vocal nuclei of songbirds (Scharff et al., 2000), and the retina of chickens (Fischer and Reh, 2001a). Common to all of these studies is the requirement for acute destruction of neurons to stimulate regeneration. This implies that the slow loss of neurons, which occurs in progressive neurodegenerative disorders, seems unlikely to prompt spontaneous neural regeneration. Thus, external intervention to induce the production of new neurons in the absence of acute damage seems a necessary step toward regenerating neurons in tissues suffering from progressive cell loss. However, the means by which to stimulate neural regeneration in the adult CNS without eliciting damage remain unknown.

As noted above, recent evidence indicates that the retina of chickens has the ability to regenerate neurons. In response to neurotoxic damage, numerous Müller glia dedifferentiate, prolif-

\footnotetext{
Received May 31, 2002; revised Aug. 12, 2002; accepted Aug. 23, 2002.

This work was supported by fellowships from the Alberta Heritage Foundation for Medical Research and the Canadian Institutes of Health Research (A.J.F.) and by National Institutes of Health Grant R01 EY13475 and National Science Foundation Grant 1BN 9604843 (T.A.R.). We thank Josh Friedland-Little for providing expert technical assistance. We also thank Drs. D. Raible and R. Kubota for their comments that helped to contribute to the final form of this manuscript. The Pax6 and BrdU antibodies developed by Drs. A. Kawakami and S. J. Kaufman, respectively, were obtained from the Developmental Studies Hybridoma Bank developed under the auspices of the National Institute of Child Health and Human Development and maintained by the Department of Biological Sciences, University of Iowa (Iowa City, Iowa).

Correspondence should be addressed to Dr. Thomas A. Reh, Department of Biological Structure, University of Washington, Box 357420, Seattle, WA 98195. E-mail: tomreh@u.washington.edu.

Copyright ( 2002 Society for Neuroscience 0270-6474/02/229387-12\$15.00/0
}

erate, express transcription factors (Cash1, Pax6, and Chx10) common to retinal progenitors, and produce new neurons (Fischer and Reh, 2001a). To investigate the molecular mechanisms responsible for this response, we tested whether exogenous growth factors are capable of stimulating Müller glia to dedifferentiate, proliferate, and produce new neurons. In response to damage, growth factors, including fibroblast growth factors (FGFs), are produced by retinal cells (Kostyk et al., 1994; Wen at al., 1995; Valter et al., 1998; Cao et al., 2001; Walsh et al., 2001). In addition, FGF has been shown to stimulate the proliferation of embryonic retinal progenitors (Lillien and Cepko, 1992; Anchan and Reh, 1995) and promote the development of ganglion cells in the retina (Pittack et al., 1991, 1997; Guillemot and Cepko, 1992; McCabe et al., 1999; Patel and McFarlane, 2000). Therefore, it is possible that FGFs produced by damaged retinal cells cause Müller glia to dedifferentiate, proliferate, and become progenitorlike cells in toxin-damaged chick retina.

Like FGFs, insulin and insulin-like growth factors (IGFs) may be involved in the Müller glial response to injury. During embryonic retinal development, IGF-I is transiently expressed by Müller glia and pigmented epithelial cells (Hansson et al., 1989; de la Rosa et al., 1994). In addition, IGF-I stimulates the proliferation of retinal progenitors (de la Rosa et al., 1994; Hernandez-Sanchez et al., 1995) and promotes the differentiation and survival of amacrine cells (Hernandez-Sanchez et al., 1995; Politi et al., 2001). Furthermore, IGF-I acts synergistically with FGF2 to stimulate the proliferation of oligodendrocyte progenitors (Jiang et al., 2001). The purpose of this study was to test whether exogenous insulin and FGF stimulate Müller glia in the chicken retina to dedifferentiate, proliferate, and produce new neurons.

We found that intraocular injection of a combination of insulin and FGF2, but not insulin or FGF2 alone, had a variety of 
influences on postmitotic Müller glia, including: (1) suppression of glutamine synthetase (GS) expression, (2) re-entry into the cell cycle in the absence of retinal damage, (3) expression of Pax6 and Chx10, and (4) production of new glia and neurons.

\section{METHODS AND MATERIALS}

Animals. The use of animals in these experiments was in accordance with the guidelines established by the National Institutes of Health and the University of Washington. Newly hatched leghorn chickens (Gallus gallus domesticus) were obtained from $\mathrm{H} \& \mathrm{~N}$ Highline International (Seattle, WA) and kept on a 16/8 hr light/dark cycle (lights on at 6:00 A.M.). Chicks were housed in clear Nalgene cages at $\sim 25^{\circ} \mathrm{C}$ and received water and Purina chick starter ad libitum.

Injections. Chicks were anesthetized and injected as described previously (Fischer and Reh, 2000). Unless specified otherwise, all injection paradigms began at postnatal day 7 (P7). The left eye (control) was injected with $20 \mu \mathrm{l}$ of vehicle [sterile saline plus $0.1 \mathrm{mg} / \mathrm{ml}$ bovine serum albumin (BSA)], and the right eye (treated) was injected with growth factors. Growth factors used in these experiments included: purified bovine insulin ( $2 \mu \mathrm{g}$ per injection), purified bovine FGF2 (100 ng per injection), recombinant human epidermal growth factor (EGF) (100 ng per injection), recombinant rat ciliary neurotrophic factor (CNTF) (100 ng per dose), and purified bovine FGF1 (100 ng per injection). All growth factors were obtained from R \& D Systems (Minneapolis, MN) and dissolved in saline plus $0.1 \mathrm{mg} / \mathrm{ml}$ BSA and $100 \mu \mathrm{g} / \mathrm{ml}$ 5-bromo-2deoxyuridine (BrdU) (Sigma, St. Louis, MO).

Fixation and sectioning. Dissection, fixation, and sectioning were performed as described previously (Fischer et al., 1998, 1999; Fischer and Reh, 2000).

Immunocytochemistry. Standard immunocytochemical techniques were applied as described previously (Fischer et al., 1998, 1999; Fischer and Reh, 2000). Working dilutions and sources of antibodies used in this study included: mouse anti-Pax6 at 1:50 [Developmental Studies Hybridoma Bank (DSHB)], rabbit anti-Chx-10 at 1:4000 (Dr. T. Jessell, Columbia University, New York, NY), mouse anti-Hu at 1:200 (Monoclonal Antibody Facility, University of Oregon, Portland, OR), rabbit antivisinin at 1:5000 (Dr. R. S. Polans, Dow Neurological Institute, Portland, OR), rabbit anti-PKC at 1:1000 (Research Diagnostics, Flanders, NJ), rabbit anti-glutamine synthetase at 1:2000 (Dr. P. Linser, University of Florida, Saint Augustine, FL), mouse anti-neurofilament at 1:2000 (recognizes the $160 \mathrm{kDa}$ isoform of neurofilament; RMO270; Zymed, South San Francisco, CA), rabbit anti-neurofilament at 1:1000 (recognizes the $145 \mathrm{kDa}$ isoform of neurofilament; Chemicon, Temecula, CA), mouse anti- $\beta 3$ tubulin at 1:1000 (TUJ-1; Covance), mouse anti-RA4 (Dr. S. McLoon, University of Minnesota, Minneapolis, MN), mouse antineurofilament at 1:80 (recognizes the phosphorylated $200 \mathrm{kDa}$ isoform of neurofilament; RT97; DSHB), rat anti-BrdU at 1:80 (Accurate Chemicals, Westbury, NY), and mouse anti-BrdU at 1:80 (G3B4; DSHB). Secondary antibodies included goat anti-rabbit-Alexa568, goat antimouse-Alexa568, goat anti-mouse-Alexa488, and goat anti-rat-Alexa488 (Molecular Probes, Eugene, OR) diluted to $1: 500$ in PBS (0.05 M phosphate buffer and $145 \mathrm{~mm} \mathrm{NaCl}, \mathrm{pH} 7.4$ ) plus $0.3 \%$ Triton X-100.

Labeling for fragmented DNA. $3^{\prime}$ nick-end labeling was performed as described previously (Fischer et al., 1998).

Measurements, cell counts, and statistical analyses. Errors were calculated as the SD of each sample that was composed of at least five individuals per group. To compare data from treated and control eyes, statistical significance was assessed by using a two-tailed Student's $t$ test or ANOVA and post hoc Student's $t$ test. All measurements were made from digital micrographs of the retinal margin, whereas all cell counts were made under the microscope on at least four different sections per individual.

\section{RESULTS}

\section{Insulin and FGF2 induce proliferation and accumulation of progenitor-like cells in the retina}

To deliver growth factors to the retina, we made one to three consecutive daily intraocular injections starting at $\mathrm{P} 7$ of insulin alone ( $2 \mu \mathrm{g}$ per dose), FGF2 alone (100 ng per dose), or insulin and FGF2 together. We assayed whether exogenous growth factors stimulate proliferation within the retina by injecting $\mathrm{BrdU}$ with the growth factors into the eye and probing for incorporation of BrdU and expression of proliferating cell nuclear antigen (PCNA) by using indirect immunofluorescence on retinal sections. In retinas treated with insulin alone (Fig. 1a) or two consecutive daily injections of insulin and FGF2 (data not shown), we found BrdU/PCNA-labeled cells only at the peripheral edge of the retina in the progenitor zone at the retinal margin. These findings are consistent with previous reports (Fischer and Reh, 2000; Fischer et al., 2002). Most (82.2 $\pm 4.1 \%)$ of the PCNA-labeled cells were BrdU-labeled within the retina. In retinas treated with FGF2 alone (data not shown), insulin alone (Fig. 1a,d), or two injections of insulin and FGF2 (data not shown), we did not find BrdU-labeled cells within the retina beyond the progenitor zone. In contrast, $6 \mathrm{hr}$ after the last of three consecutive daily injections of insulin and FGF2, we found numerous BrdU-labeled cells in the retina (Fig. 1b,e). These BrdU-labeled cells were found near the center of the inner nuclear layer (INL), and some were in the outer nuclear layer (ONL) (Fig. 1b). Six hours after the last of three consecutive daily injections of insulin and FGF2, the percentage of BrdU/PCNAlabeled cells within the retina was reduced $(40.9 \pm 13.8 \%)$, with many PCNA-positive/BrdU-negative cells in more central regions of the retina (Fig. 1b,e). Forty-eight hours after the final injection of insulin and FGF2, BrdU-labeled nuclei were found scattered throughout the ONL and INL, farther away from the retinal margin $(\leq 600 \mu \mathrm{m})$ than those observed at $6 \mathrm{hr}$ after the final injection (Fig. 1c). Forty-eight hours after the last injection of insulin and FGF2, the percentage of BrdU/PCNA-labeled cells within the retinal section was reduced $(10.1 \pm 8.3 \%)$ from that observed at $6 \mathrm{hr}$ after the final injection of growth factors. This percentage was region specific; within $500 \mu \mathrm{m}$ of the retinal margin, $38.1 \pm 7.6 \%$ of the PCNA-expressing cells were labeled for BrdU (Fig. 1g), whereas within $>600 \mu \mathrm{m}$ from the retinal margin, none of the PCNA-expressing cells were labeled for BrdU (Fig. 1 $f$ ). Ten days after the final injection of insulin and FGF2, numerous BrdU-labeled cells remained in the retina, in a pattern similar to that observed at $48 \mathrm{hr}$ after the final injection of growth factors. BrdU-labeled cells were found only in peripheral regions of the retina, within $1 \mathrm{~mm}$ of the retinal margin, whereas PCNA-labeled cells were found in $\leq 2.5 \mathrm{~mm}$ from the retinal margin. These findings indicate that BrdU applied with the final injection of growth factors is cleared from the eye within $48 \mathrm{hr}$ and fails to label all PCNAexpressing proliferating cells. In addition, these findings suggest that insulin and FGF2 initiate a wave of proliferating cells within the retina that begins in the far peripheral retina and progresses toward more central regions with increasing time after the injection of insulin and FGF2.

To test whether insulin and FGF2 induce a wave of proliferating cells, we made three consecutive daily injections of these growth factors without BrdU and provided BrdU at different times after the final injection of growth factors. In retinas that were treated with BrdU $6 \mathrm{hr}$ after the final injection of insulin and FGF2, we observed many BrdU/PCNA-labeled cells within the peripheral retina, within $500 \mu \mathrm{m}$ of the retinal margin, but not including substantial numbers of cells within the progenitor zone (Fig. 2a,e). We also found many cells labeled for PCNA alone, extending $\sim 700 \mu \mathrm{m}$ into the retina (Fig. $2 a, e$ ). In eyes that were injected with BrdU $12 \mathrm{hr}$ after the final injection of insulin and FGF2, we found an area of BrdU/PCNA-labeled cells, $\sim 700 \mu \mathrm{m}$ wide, near the retinal margin (Figs. $2 b, f$ ). We also found many cells labeled for PCNA alone extending $\sim 1000 \mu \mathrm{m}$ into the retina 


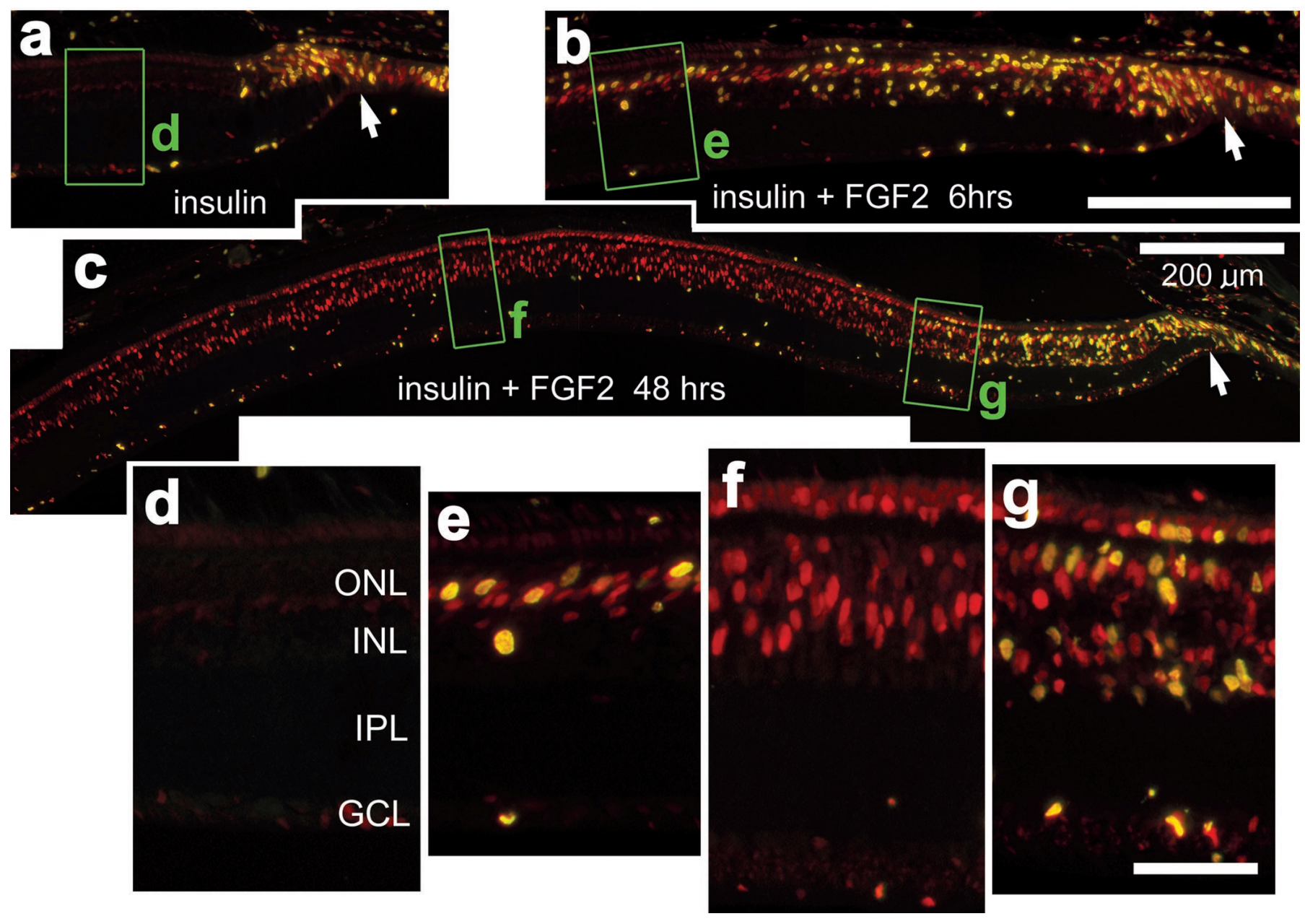

Figure 1. Exogenous insulin and FGF2 stimulate the proliferation of cells within peripheral regions of the retina. Vertical sections of the retina were labeled with antibodies to PCNA (in red) and BrdU (in green). Cells double labeled for PCNA and BrdU appear yellow, because all BrdU-labeled cells express PCNA. $a-c$, Montage images of retinas from eyes that received three consecutive daily injections of BrdU with insulin $(a, d)$ or insulin with FGF2 $(b, c, e-g)$. Injections were made from $\mathrm{P} 7$ through $\mathrm{P} 9$, and eyes were harvested $6 \mathrm{hr}(b, e), 24 \mathrm{hr}(a, d)$, or $48 \mathrm{hr}(c, f, g)$ after the final injection. $d-g$, Enlarged images of the areas boxed out in green in $a-c$. Arrows, Retinal margin. Scale bars: $b$ (for $a, b$ ), $c$ (for $d-f$ ), $200 \mu \mathrm{m} ; g, 50 \mu \mathrm{m}$. GCL, Ganglion cell layer.

(Fig. $2 b, f$ ). When BrdU was injected $24 \mathrm{hr}$ after the final injection of insulin and FGF2, we observed numerous BrdU/PCNAlabeled cells that extended over $1 \mathrm{~mm}$ into the retina (Fig. $2 c, g$ ). When BrdU was injected $48 \mathrm{hr}$ after the final injection of insulin and FGF2, we observed relatively few BrdU-labeled cells scattered across the retina, whereas numerous PCNA-labeled cells were found scattered within the peripheral retina $\sim 2.5 \mathrm{~mm}$ from the retinal margin (Fig. $2 d$ ). With increasing time after the final injection of insulin and FGF2, the region in which BrdU- and PCNA-labeled cells were observed increased in size, spreading from the far peripheral retina toward more central regions. The greatest number of BrdU-labeled cells appeared when BrdU was applied $24 \mathrm{hr}$ after the final injection of growth factors (164.3 \pm 25.4 cells per section) (Fig. $2 c$ ), compared with numbers observed when BrdU was applied at $6 \mathrm{hr}$ (38.8 \pm 8.5 cells per section), 12 $\mathrm{hr}(63.1 \pm 12.7$ cells per section $)$, or $48 \mathrm{hr}(59.5 \pm 21.2$ cells per section). Together, these findings indicate that three consecutive daily injections of insulin and FGF2 induce a wave of proliferating cells that begins at the retinal margin and propagates several millimeters toward central regions of the retina.

Because we observed proliferating cells only in retinas that received three, but not two, consecutive daily doses of insulin and
FGF2, we sought to test whether this was a cumulative effect. These three doses would have totaled $6 \mu \mathrm{g}$ of insulin and $300 \mathrm{ng}$ of FGF2 delivered to an eye. Accordingly, we gave a single large injection of insulin $(6 \mu \mathrm{g})$ and FGF2 (500 $\mathrm{ng})$ and harvested the eyes $24 \mathrm{hr}$ later. We found that a single large dose of insulin and FGF2 did not stimulate the proliferation of cells within the retina. This finding suggests that repeated low doses or sustained levels of insulin and FGF2 are required to stimulate the proliferation of cells within the retina.

Because EGF has been shown to stimulate the proliferation of progenitors at the retinal margin of chickens (Fischer and Reh, 2000), we tested whether EGF stimulated the proliferation of cells within the retina. In eyes that received three consecutive daily injections of EGF alone or EGF with insulin, we did not observe the proliferation of cells within the retina (data not shown). Because CNTF is expressed at increased levels in damaged retinas (Cao et al., 2001) and Müller glia proliferate in damaged retinas (Fischer and Reh, 2001a), we tested whether CNTF stimulated the proliferation of Müller glia. In eyes treated with three consecutive daily injections of CNTF alone or CNTF with insulin, we did not observe proliferating cells within the retina (data not shown). 


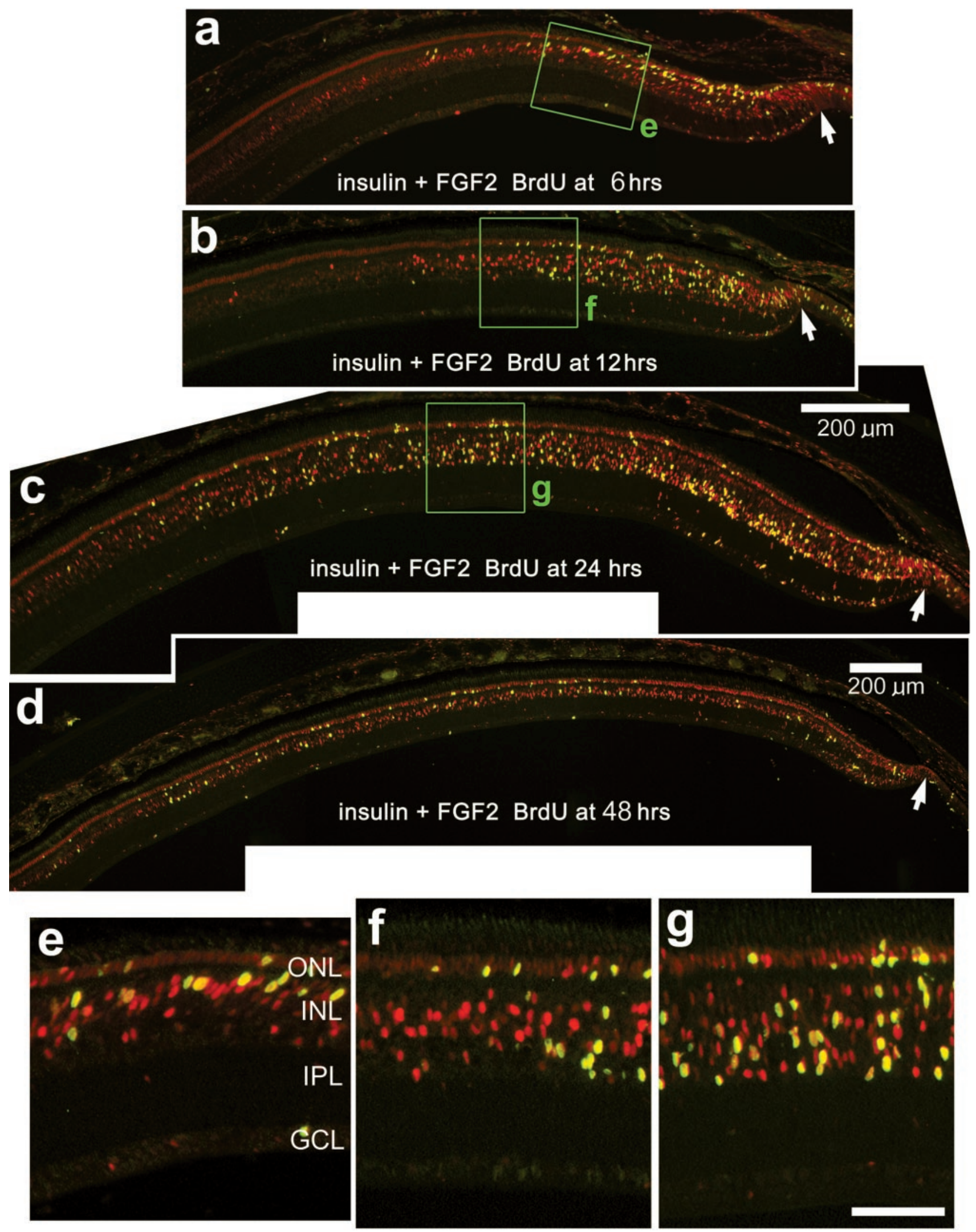

Figure 2. Insulin and FGF2 induce a wave of proliferating cells that begins at the retinal margin and proceeds toward central regions of the retina. Vertical sections of the retina were labeled with antibodies to PCNA (in red) and BrdU (in green). Cells double labeled for PCNA and BrdU appear yellow, because all BrdU-labeled cells express PCNA. $a-d$, Retinas were obtained from eyes that received three consecutive daily injections of insulin and FGF2 (without $\mathrm{BrdU})$. Injections of growth factors were made from P7 through P9, and a single injection of BrdU was made at $6 \mathrm{hr}(a), 12 \mathrm{hr}(b), 24 \mathrm{hr}(c)$, or $48 \mathrm{hr}(d)$ after the final injection of growth factors. Eyes were harvested $6 \mathrm{hr}(a), 12 \mathrm{hr}(b)$, or $24 \mathrm{hr}(c, d)$ after the injection of BrdU.e-g, Images are enlarged from the areas boxed out in green in $a-d$. Arrows, Retinal margin. Scale bars: $c$ (for $a-c$ ), $200 \mu \mathrm{m} ; g$ (for $e-g$ ), $50 \mu \mathrm{m}$. $G C L$, Ganglion cell layer. 

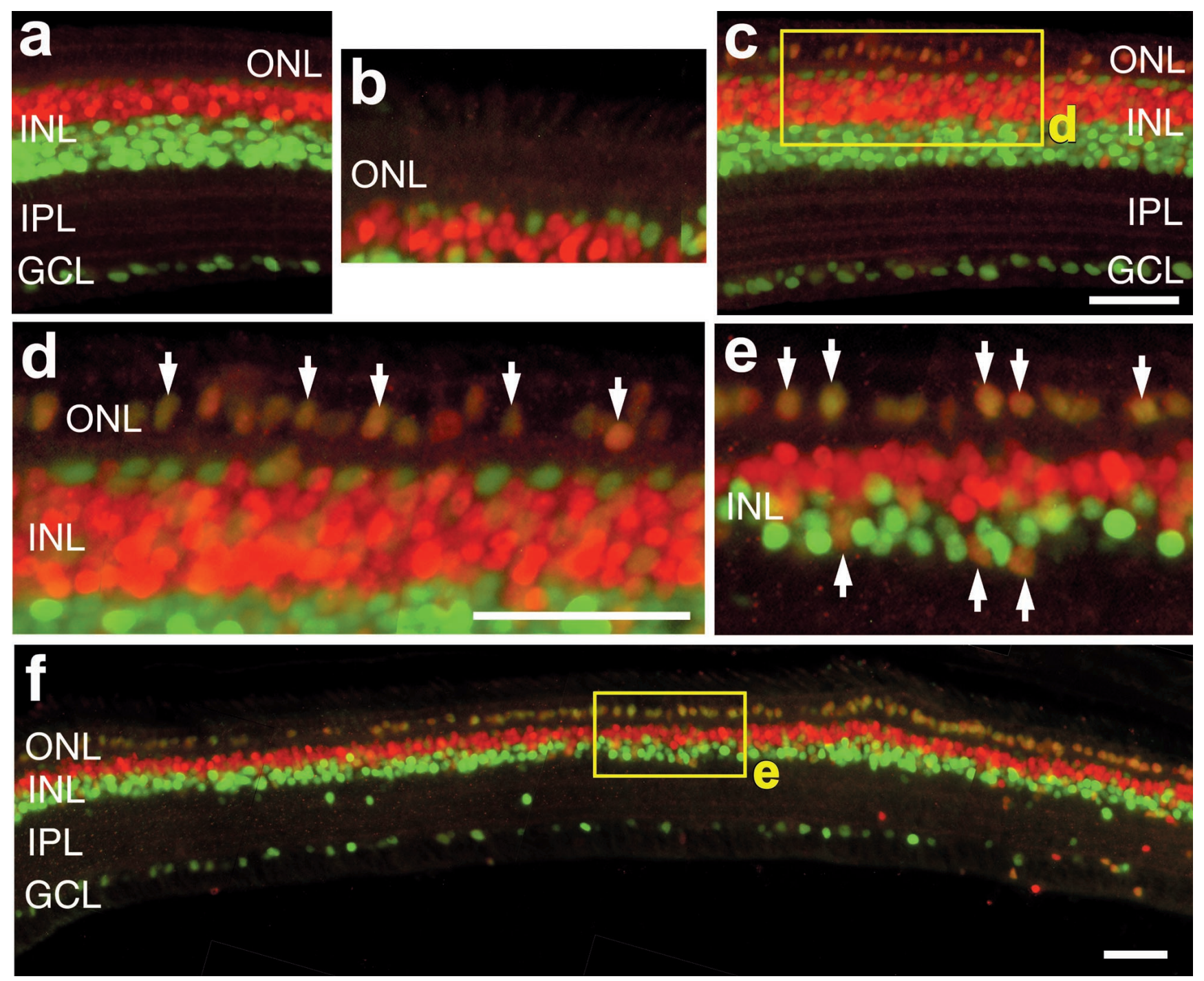

Figure 3. Insulin and FGF2 induce the accumulation of progenitor-like cells that coexpress Pax6 and Chx10 in the retina. Retinas were treated with three consecutive injections of insulin $(a, b)$ or insulin and FGF2 $(c-f)$. Retinas were processed for immunocytochemistry 24 hr $(a-d)$ or $10 \mathrm{~d}(e, f)$ after the final injection. Cells labeled for Pax6 alone are green, cells labeled for Chx10 alone are red, and cells labeled for both Pax6 and Chx10 are yellow-orange. The yellow rectangles in $c$ and $f$ are enlarged in $d$ and $e$, respectively. The small arrows in $d$ and $e$ indicate cells double labeled for Pax6 and Chx10. Scale bars: $c$ (for $a, c), d$ (for $b, d, e$ ), $50 \mu \mathrm{m}$. GCL, Ganglion cell layer.

\section{Insulin and FGF2 induce the accumulation of progenitor-like cells within peripheral regions of the retina}

To test whether progenitor cells accumulated in peripheral regions of growth factor-treated retinas, we double labeled sections with the antibodies Pax6 and Chx10. These homeodomain transcription factors are known to be coexpressed by embryonic retinal progenitors (Belecky-Adams et al., 1997), progenitors at the retinal margin of postnatal chickens (Fischer and Reh, 2000), and Müller glia-derived progenitors in acutely damaged chicken retina (Fischer and Reh, 2001a).

In saline-treated retinas, Pax6/Chx10-coexpressing cells were observed only at the retinal margin (data not shown), consistent with our previous report (Fischer and Reh, 2000). Injections of FGF2 or insulin alone did not affect the distribution of Pax6/ Chx10-coexpressing cells at the retinal margin or within the retina (Fig. 3a,b). Twenty-four hours after the last of three consecutive daily injections of insulin with FGF2, there was a marked induction of Pax6/Chx10-immunoreactive cells within the retina; these cells were found within $1 \mathrm{~mm}$ of the retinal margin (Fig. $3 c, d$ ). Ten days after the final injection of insulin and FGF2, we found numerous Pax6/Chx10-immunoreactive cells scattered throughout the ONL and INL (Fig. 3e,f). All Pax6-labeled cells in the ONL were colabeled for Chx10 $(n=345)$. Similar to the distribution of BrdU-labeled cells, the accumulation of progenitor-like cells was not observed in central regions of the retina but was confined to peripheral regions of the retina within $2.5 \mathrm{~mm}$ of the retinal margin. Pax6/Chx10-expressing cells in the ONL decreased in abundance with increasing distance from the retinal margin (Fig. 3f). These observations were consistent for all eyes treated with the combination of insulin and FGF2 $(n=10$ for 24 hr after the final dose; $n=5$ for $10 \mathrm{~d}$ after the final dose). Pax6/Chx10-double-labeled cells were never observed within retinas treated with FGF2 alone $(n=6)$, insulin alone $(n=12)$ (Fig. $3 a, b)$, or one to two consecutive daily doses of both insulin and FGF2 ( $n=5$ for both one and two doses). 


\section{Müller glia proliferate and express Pax6 in response to insulin and FGF2}

The patterns of labeling for BrdU, Pax6, and Chx10 are similar to those observed in toxin-treated retinas, where Müller glia give rise to proliferating progenitor-like cells (Fischer and Reh, 2001a). To test whether Müller glia re-enter the cell cycle in retinas treated with insulin and FGF2, we coinjected BrdU with growth factors into eyes, dissected and fixed the retinas at different times after injection, and then labeled retinal sections with antibodies to BrdU and the Müller glial marker GS. Six hours after the final injection of insulin and FGF2, we found that $77.9 \%$ (127 of 163 cells counted from six individuals) of the BrdUlabeled cells in the INL were GS-expressing Müller glia (Fig. $4 a-c)$. However, at $24 \mathrm{hr}$ after the final injection of insulin and FGF2, we did not find any clear examples of BrdU-labeled cells that were immunoreactive for GS (data not shown). These findings suggest that between 6 and $24 \mathrm{hr}$ after the final injection, many Müller glia re-enter the cell cycle and reduce their expression of GS before migrating to the ONL. To further confirm this finding, we double labeled retinal sections with antibodies to PCNA and GS. Six hours after the final injection of insulin and FGF2, we found that all PCNA-labeled cells within the INL were colabeled for GS (226 cells counted from six individuals) (Fig. 4d,e).

Because we observed the accumulation of Pax6/Chx10coexpressing cells within the retina, we tested whether BrdUlabeled cells expressed Pax6. In retinas treated with insulin and FGF2, some of the BrdU-labeled cells in the INL and ONL were immunoreactive for Pax6 (Fig. 3g-i). Although the high density of Pax6/BrdU labeling in the INL made it difficult to clearly distinguish double-labeled cells, we were able to determine that $90.7 \%$ (137 of 151 counted from four individuals) of the BrdU-labeled cells in the ONL were colabeled for Pax6. The identity of the BrdU-positive/Pax6-negative cells remains uncertain. Of the Pax6-labeled cells in the ONL, $45.5 \pm 10.7 \%$ (mean \pm SE) (127 of 300 cells counted from four individuals) were labeled for BrdU, suggesting that some of the Pax6-expressing cells in the ONL may not have been dividing, or that these cells were in $\mathrm{S}$ phase at a time when BrdU was no longer present in the eye.

We tested whether the combination of insulin and FGF2 stimulates Müller glia proliferation and subsequent transformation into progenitor-like cells in older animals by starting the injection paradigm at P24 instead of P7. Similar to the effects of insulin and FGF2 in younger animals, we observed cells in peripheral regions of the retina that were labeled for BrdU, PCNA, Pax6, and Chx10 (data not shown).

\section{Identification of newly generated cells in the retina}

The proliferation of Müller glia after injection of insulin and FGF2 was similar to that reported for Müller glia in toxindamaged retinas (Fischer and Reh, 2001a). After neurotoxic damage, Müller glia give rise to numerous progenitor-like cells, new glia, and new neurons (Fischer and Reh, 2001a). To identify the types of cells produced by Müller glia in response to insulin and FGF2, we labeled retinal sections obtained from growth factor-treated eyes $14 \mathrm{~d}$ after the final injection with antibodies to BrdU and GS, Pax6, or the neuron-specific markers visinin, PKC, $\mathrm{Hu}$, or calretinin. We found that $\sim 24 \%$ of the Müller glia-derived cells formed new Müller glia, as judged by colabeling for BrdU and GS (Figs. 5a-c, 6). Most of the newly formed cells appeared to be progenitor-like cells with continued expression of Pax6 (Figs. 5d-f, 6). We never observed BrdU-labeled cells that ex- pressed the photoreceptor marker visinin or the bipolar cell marker PKC (Figs. $5 g-i, 6$ ). However, we found that $\sim 4 \%$ of the BrdU-labeled cells were immunoreactive for $\mathrm{Hu}$ (Figs. $5 j-l, 6$ ). $\mathrm{Hu}$ is an RNA-binding protein related to the ELAV proteins of Drosophila and is expressed by neurons soon after they begin to differentiate (Marusich et al., 1994; Barami et al., 1995). In the chick retina, $\mathrm{Hu}$ is expressed by most if not all amacrine and ganglion cells (Fischer and Reh, 2000, 2001). BrdU/Hu-labeled cells had a variety of morphologies and were found in different retinal layers. Many of these cells were found in the inner plexiform layer (IPL), whereas others were found within the amacrine cell layer of the INL (Fig. $5 j-l$ ). To corroborate the findings of $\mathrm{BrdU} / \mathrm{Hu}$ labeling, we also found BrdU-labeled cells that expressed calretinin in the amacrine cell layer of the INL (Fig. $5 m-o)$. Calretinin is a calcium-binding protein that is expressed by horizontal, amacrine, and ganglion cells in the chick retina (Rogers, 1989; Rogers et al., 1989; Ellis et al., 1991; Fischer et al., 1999). All calretinin-expressing amacrine cells are $\mathrm{Hu}$ positive, but not all $\mathrm{Hu}$-expressing amacrine cells are calretinin positive (data not shown). Cells double labeled for $\mathrm{BrdU}$ and $\mathrm{Hu}$ or calretinin were in peripheral regions of the retina, $\leq 2.5 \mathrm{~mm}$ from the retinal margin. We detected $\mathrm{BrdU} / \mathrm{Hu}$ - or BrdU/calretininlabeled cells only in retinas treated with three consecutive daily doses of insulin and FGF2, whereas other combinations of growth factors did not produce BrdU/Hu or BrdU/calretinin-labeled cells. The expression of $\mathrm{Hu}$ or calretinin was never observed in cells with the morphology of Müller glia, in cells that expressed GS, or in BrdU-labeled cells $1 \mathrm{~d}$ after the final injection of growth factors.

At $12 \mathrm{~d}$ after the final injection of growth factors, we found some cells that coexpressed Pax6 and GS in the INL (Fig. 7a-c) and ONL (Fig. $7 d-f$ ). Because Pax6 is expressed by horizontal and amacrine cells in the INL, we surveyed the percentage of Pax6-positive cells that expressed GS in the ONL. We found that $35.6 \pm 11.1 \%$ of the Pax6-labeled cells in the ONL were colabeled with antibodies to GS (83 cells surveyed from four individuals).

\section{Labeling for apoptotic cells}

Because the response of Müller glia to insulin and FGF2 was similar to that observed with neurotoxic damage, we tested whether intraocular injections of growth factors induced programmed cell death. We probed for fragmented DNA by using the terminal deoxynucleotidyl transferase-mediated biotinylated UTP nick end labeling (TUNEL) method at $6 \mathrm{hr}, 12 \mathrm{hr}, 1 \mathrm{~d}, 2 \mathrm{~d}$, or $3 \mathrm{~d}$ after the final injection. One, two, or three consecutive daily applications of insulin alone (Fig. 8a), FGF2 alone (Fig. 8b), or insulin and FGF2 (Fig. $8 c$ ) did not induce TUNEL-labeled nuclei at the retinal margin or in more central regions of the retina at any time after the final injection. These findings indicate that the proliferation and transdifferentiation of Müller glia induced by exogenous insulin and FGF2 were not secondary to damage to retinal neurons.

\section{DISCUSSION}

Here we report that exogenous insulin and FGF2 induce a response in Müller glia that is similar to that observed after neurotoxic damage. We found that insulin and FGF2 (1) suppressed the expression of GS by Müller glia, (2) stimulated Müller glia to express Pax6 and PCNA, (3) induced the accumulation of progenitor-like cells in peripheral regions of the retina, (4) stimulated Müller glia to re-enter the cell cycle within $2 \mathrm{~d}$ after the 


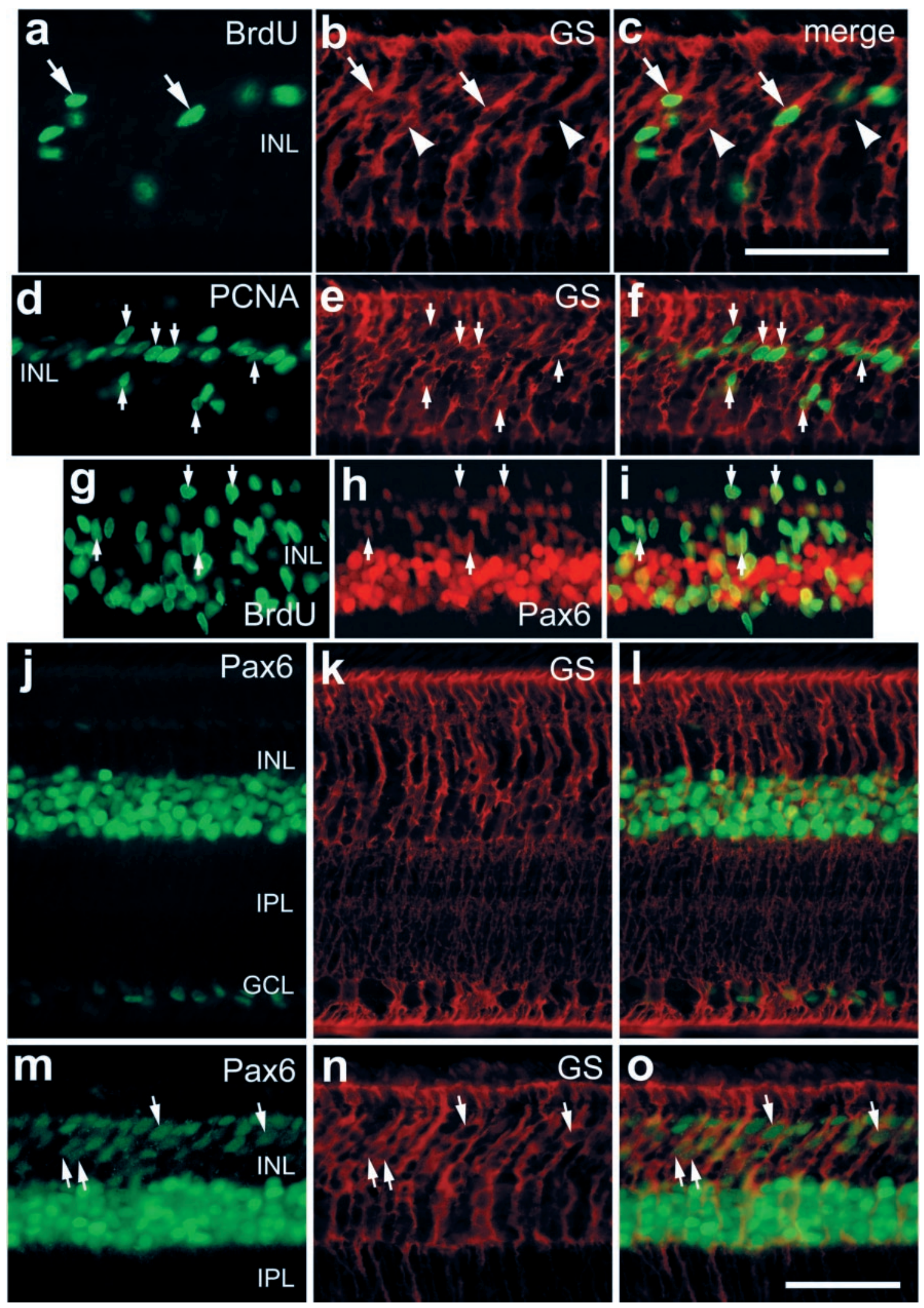

Figure 4. Insulin and FGF2 stimulate Müller glia to re-enter the cell cycle and express PCNA and Pax6. Eyes received three consecutive daily injections of insulin and FGF2 $(a-i, m-o)$ or insulin alone $(j-l)$, and tissues were harvested $6 \mathrm{hr}$ after the final injection. $a-f$, Vertical sections of the retina that were labeled for GS (in red) and BrdU (in green) $(a, c)$ or PCNA (in green) $(d, f)$ are shown. Small arrows, Cells that are double labeled for GS and BrdU $(a-c)$ or GS and PCNA $(d-f)$. Arrows, Cells double labeled for GS and BrdU or PCNA; arrowheads, cells labeled for GS alone. $g-i$, Vertical sections of the retina that were labeled for BrdU (in green) and Pax6 (in red). Arrows, Cells that are double labeled for BrdU and Pax6. $j-l$, Vertical sections of the retina that were labeled for Pax6 (in green) and GS (in red). Arrows, Cells that were double labeled for Pax6 and GS. Scale bars: $c$ (for $a-c$ ), $o$ (for $d-o), 50 \mu \mathrm{m}$. GCL, Ganglion cell layer. 

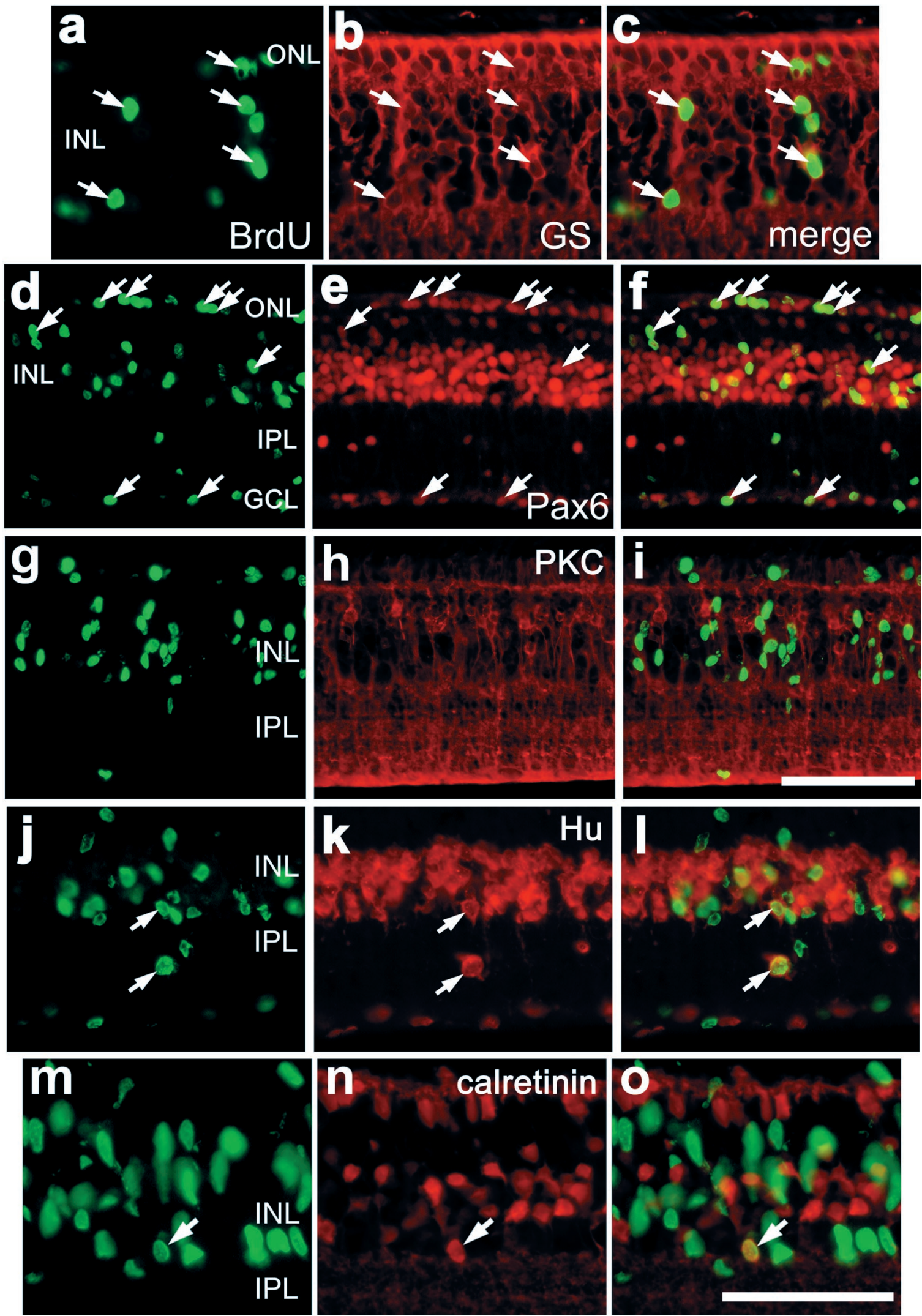

Figure 5. Some of the proliferating cells in growth factor-treated retinas differentiate into Müller glia or neurons, whereas most remain undifferentiated with continued expression of Pax6. Vertical sections of the retina were labeled with antibodies to $\operatorname{BrdU}(a, d, g, j, m)$ and GS $(b)$, Pax6 $(e)$, PKC $(h)$, $\mathrm{Hu}(k)$, or calretinin $(n) . c, f, i, l, o$, Overlay images of the panels immediately to their left. Arrows, Double-labeled cells. $G C L$, ganglion cell layer. Scale bars: $i$ (for $d-i), o$ (for $a-c, j-o$ ), $50 \mu \mathrm{m}$. 


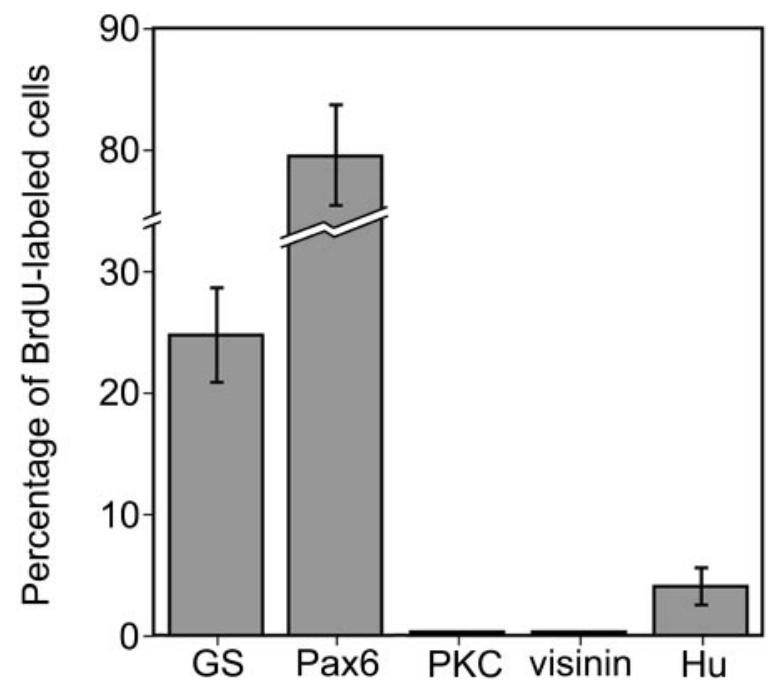

Figure 6. Histogram illustrating the relative percentages of cell types that were labeled with BrdU $14 \mathrm{~d}$ after the final injection of growth factors. Retinas were obtained from eyes that received three consecutive daily injections of insulin and FGF2. Cell counts were made on vertical retinal sections that were immunolabeled for BrdU and Pax6, GS, Hu, $\mathrm{PKC}$, or visinin.

final injection of growth factors, and (5) stimulated the production of new glia and neurons within peripheral regions of the retina. These results are summarized in Figure 9. All of these effects were observed in the absence of retinal damage, as indicated by the absence of TUNEL-labeled cells.

In response to insulin and FGF2, proliferating Müller glia rapidly downregulate their expression of GS. Similarly, in toxintreated eyes, we have reported that BrdU labeling first appears in GS-positive Müller glia that express neurofilament, and, subsequently, these cells downregulate their expression of GS (Fischer and Reh, 2001a). In the current study, we found BrdU labeling in GS-positive Müller glia at $6 \mathrm{hr}$ but not $24 \mathrm{hr}$ after treatment with insulin and FGF2. This suggests that insulin and FGF2 rapidly suppressed GS expression in proliferating Müller glia. Consistent with findings presented here, a recent report by Kruchkova et al. (2001) demonstrated that in explant cultures of chick retina, FGF2 decreases the expression of GS in Müller glia.

We propose that the proliferating progenitor-like cells that accumulated in peripheral regions of the retina were derived from Müller glia. Shortly after the last of three consecutive daily injections of insulin and FGF2, we observed numerous GSexpressing Müller glia that accumulated BrdU and expressed PCNA and Pax6. Twenty-four hours after the final injection of growth factor, we found that all of the Pax6-expressing cells that accumulated in the ONL coexpressed Chx10, suggesting that the Pax6/GS-positive cells observed $\sim 18 \mathrm{hr}$ earlier had migrated into the ONL and turned on Chx10. This result is reminiscent of the response of Müller glia in toxin-damaged chick retina (Fischer and Reh, 2001a). Two days after toxin treatment, numerous Müller glia-derived cells express Pax6 and Chx10, these cells accumulate in the ONL and INL, and most of these cells remain undifferentiated for at least several weeks with continued expression of these transcription factors. Thus, it seems likely that toxin treatment and growth factor injections induce the same response: the generation of $\mathrm{Pax} / \mathrm{Chx} 10$-positive progenitor-like cells from Müller glia.

The significance of Pax6/GS-expressing cells remains uncer- tain. Twelve days after the final injection of insulin and FGF2, we found that approximately one-third of the Pax6-labeled cells in the ONL expressed GS, whereas the majority of Pax6 cells did not. GS-expressing Müller glia normally do not express Pax6 (Fig. 4); therefore, the Pax6/GS-expressing cells may not be Müller glia. Aside from glial cells, GS may be expressed at low levels by progenitor cells in the embryonic chick retina. For example, Linser et al. (1997) found that late during embryonic retinal development, proliferating progenitors express some of the markers, including GS, of mature Müller glia. Interestingly, Müller glia share a number of markers with neural progenitors; these markers include glutamate transporter (Shibata et al., 1997; Hartfuss et al., 2001), vimentin (Noctor et al., 2002), glial fibrillary acidic protein (Levitt and Rakic, 1980; Sancho-Tello et al., 1995), and nestin (in stressed glial cells) (Lendahl et al., 1990; Close et al., 2000). Thus, the Pax6/GS-expressing cells that we observed in growth factor-treated retinas may be late-stage retinal progenitors. Alternatively, the Pax6/GS-expressing cells that we observed in retinas treated with insulin and FGF2 may be arrested in a transitional phenotype, because the Pax6/GS-expressing cells were present $\sim 2$ weeks after the final injection of growth factor. Furthermore, all Pax6-expressing cells in the ONL coexpress the progenitor/bipolar cell-specific transcription factor Chx10 (Fig. 3). Similar observations have been made in the chick retina after NMDA-induced excitotoxicity, where numerous Pax6/Chx10expressing cells accumulate and remain within the retina for several weeks after toxin treatment (Fischer and Reh, 2001a).

Injections of growth factors caused the generation of some new neurons. These new neurons in peripheral regions of the retina could have been produced by progenitors at the retinal margin, quiescent stem cells seeded within the retina, or Müller glia. It is unlikely that newly generated neurons within the retina were derived from progenitors at the retinal margin. The neurons were found between 0.2 and $2 \mathrm{~mm}$ away from the retinal margin, well past the region where BrdU-labeled cells derived from progenitors at the margin accumulate in retinas treated with insulin alone (Fischer and Reh, 2000). Therefore, unless exogenous insulin and FGF2 stimulated the lateral migration of newly generated neurons derived from progenitors at the retinal margin, new neurons within the peripheral retina were derived from a source intrinsic to the retina. We cannot exclude the possibility that quiescent stem cells seeded within the retina produced new neurons in response to insulin and FGF2. For example, quiescent stem cells seeded within the retina have been identified in adult goldfish (Otteson et al., 2001) and rainbow trout (Julian et al., 1998), and these stem cells give rise to the well described rod progenitors of the teleost retina. Such quiescent neural stem cells may also exist in the postnatal chicken retina, but there is no evidence to support this hypothesis. We propose that Müller glia are the source of new neurons in peripheral retinal regions of growth factor-treated eyes. The findings presented here are similar to data from acutely damaged chick retina, where proliferating Müller glia give rise to progenitor-like cells and new neurons (Fischer and Reh, 2001a). The major difference between the behavior of Müller glia in toxin-treated and growth factor-treated retinas is the absence of cell death in retinas treated with growth factors.

The combination of insulin and FGF2 was required to stimulate Müller glia to dedifferentiate and become progenitor-like cells. The combination of these factors seems to be required for several different phenomena in the avian retina. In the postnatal chick eye, we have reported recently that the combination of insulin and FGF2 induces the production of ganglion cells from 

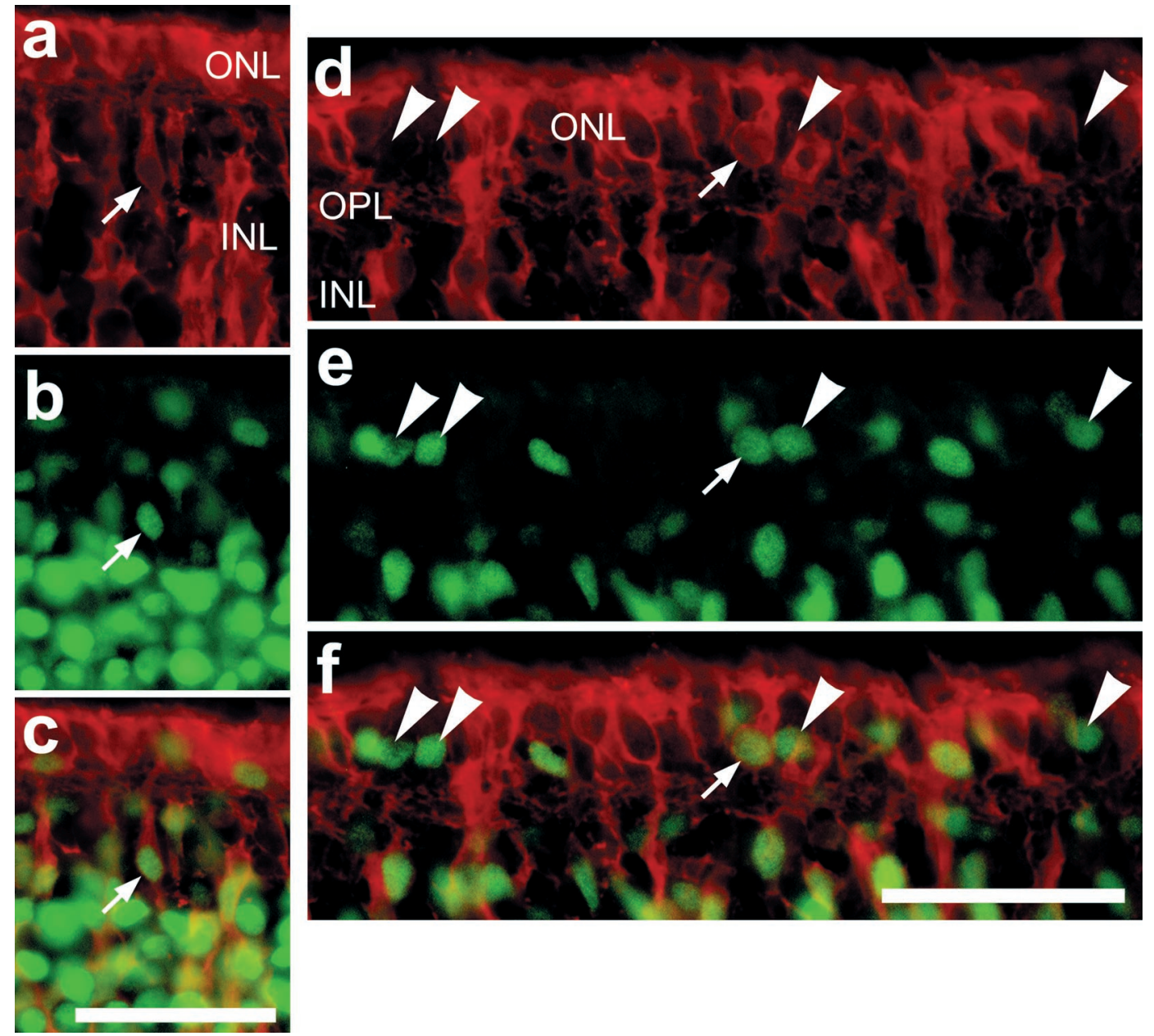

Figure 7. Twelve days after the final injection of insulin and FGF2, cells in the outer and inner nuclear layers coexpress GS and Pax6. Vertical sections of the retina were labeled with antibodies to GS $(a, d)$ and Pax6 $(b, e)$. Retinas were obtained from eyes $12 \mathrm{~d}$ after the last of three consecutive daily injections of insulin and FGF2 starting at P7. Arrows, Cells double labeled for GS and Pax6; large arrowheads, cells that are labeled for Pax6 alone. Scale bars: $c$ (for $a-c), f$ (for $d-f$ ), $50 \mu \mathrm{m}$. OPL, Outer plexiform layer.

Figure 8. Apoptotic nuclei were not found in retinas treated with growth factors. Vertical sections of the peripheral retina were obtained from eyes that received three consecutive daily doses of insulin alone $(a), \mathrm{FGF} 2$ alone $(b)$, or insulin and FGF2 (c). Apoptotic nuclei were not detected at any time $(6,24$, or $48 \mathrm{hr}$ ) after the final injection of insulin and FGF2. GCL, Ganglion cell layer. Scale bars: $b$ (for $a, b$ ), $c, 50 \mu \mathrm{m}$.
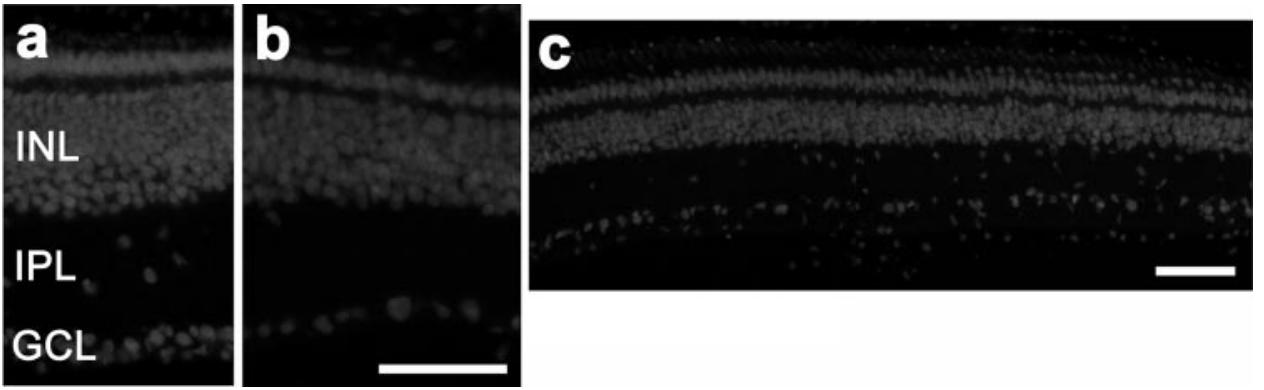

progenitors at the retinal margin (Fischer et al., 2002), stimulates the transdifferentiation and proliferation of pigmented cells in the pars plana (Fischer and Reh, 2001b), stimulates Müller glia to transiently express neuronal proteins (A. J. Fischer and T. A. Reh, unpublished observations), and stimulates the nonpigmented epithelium of the ciliary body to proliferate and produce neurons (Fischer and Reh, unpublished observations). Data presented here also suggest that sustained levels of insulin and FGF2 or repeated activation of receptors are required to stimulate Müller glia, because a single large dose of insulin and FGF2 had no effect. In comparison, EGF has been shown to stimulate the proliferation of Müller glia from the rabbit retina in vitro (Scherer and Schnitzer, 1994), intraocular injections of FGF2 stimulate the proliferation of Müller glia in the rabbit retina (Lewis et al., 1992), and FGF1 and FGF2 have been shown to stimulate the proliferation of Müller glia from the bovine retina in vitro (Mascarelli et al., 1991). Together, these findings indicate that Müller glia in the retina of warm-blooded vertebrates can be stimulated to re-enter the cell cycle by exogenous growth factors.

It remains uncertain why Müller glia in peripheral regions of retina are more responsive to insulin and FGF2 than Müller glia in central regions of retina. During embryonic retinal histogenesis, Müller glia in central regions of the retina are produced before those in peripheral regions (Prada et al., 1991). The Müller 


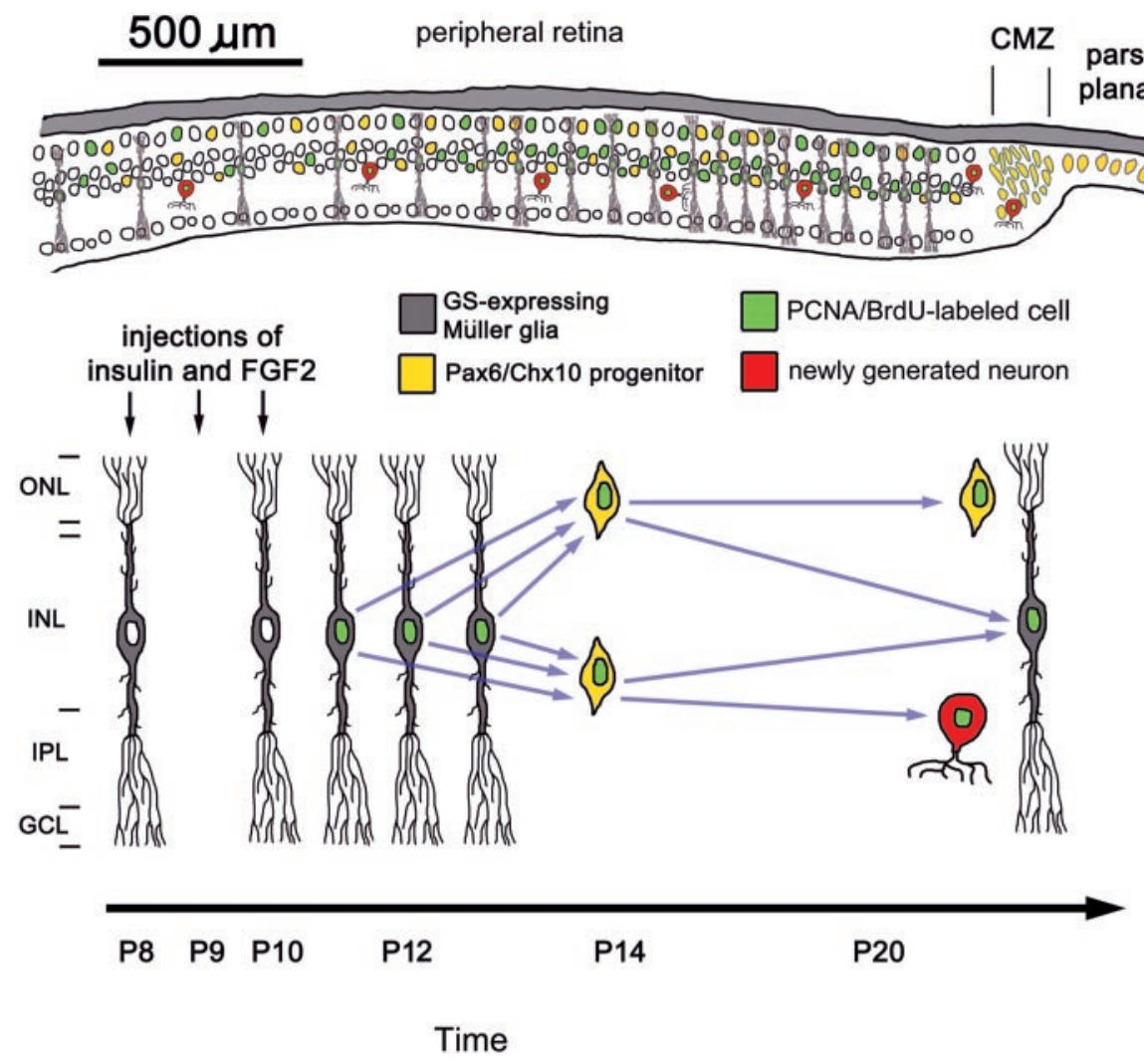

Figure 9. Diagrams summarizing the responses of Müller glia to intraocular injections of insulin and FGF2 and the region of the retina in which the responses occur. The thickness of the retina is not drawn to scale in the top panel, whereas the radial diameter matches the scale bar $(500 \mu \mathrm{m})$. CMZ, Ciliary marginal zone; $G C L$, ganglion cell layer. glia in peripheral regions of the retina may be less mature than those in more central regions; thus, they may retain a greater degree of plasticity in their phenotype. Alternatively, the Müller glia in peripheral regions of the retina may express higher levels of receptors for insulin and FGF2 or signal transduction machinery compared with those glia found in more central regions of the retina. Consistent with the notion that Müller glia in peripheral regions of the retina are less mature, we have found that toxininduced damage after $\mathrm{P} 7$ results in the proliferation and transdifferentation of Müller glia only in peripheral regions of the retina; this region of damage-responsive glia becomes increasingly confined to more peripheral regions with increasing age, up to P30 (Fischer and Reh, unpublished observations). A gradient of maturity for Müller glia in peripheral regions of the retina may underlie the wave of glial proliferation that begins at the retinal margin and spreads into the peripheral retina. It is possible that relatively immature glia in more peripheral regions of the retina re-enter the cell cycle before more mature glial in more central regions of the retina. Alternatively, growth factor-induced proliferation of glia near the retinal margin may initiate a cascade of events that stimulates neighboring glia to re-enter the cell cycle.

The ability of glia to generate new neurons has been addressed by several recent studies. Recent reports have demonstrated that during embryonic development, proliferating "radial glia" produce new neurons and astrocytes (Malatesta et al., 2000; Noctor et al., 2001). The findings of these studies suggest that the term radial glia should be replaced with the term "radial progenitor." In addition, in the adult mammalian forebrain, astrocyte-like cells may be the source of neural stem cells in the subventricular zone (Doetsch et al., 1999; Laywell et al., 2000; for review, see AlvarezBuylla et al., 2000, 2001) and hippocampus (Seri et al., 2001). Furthermore, Heins et al. (2002) have demonstrated that astrocytes in rodent cortex are capable of generating new neurons with forced expression of Pax6. Together with the findings presented in the current study, we propose that under certain circumstances, proliferating glia are a potential source of neurogenesis and neural regeneration in the CNS. The data presented here demonstrate that new neurons can be derived from glia without destroying pre-existing neurons. Because damage is not required to stimulate neurogenesis from Müller glia, we propose that insulin and FGF2 may be used to stimulate neural regeneration from Müller glia in retinas that have suffered cell losses from progressive degenerative phenomenon.

\section{REFERENCES}

Alvarez-Buylla A, Herrera DG, Wichterle H (2000) The subventricular zone: source of neuronal precursors for brain repair. Prog Brain Res 127:1-11.

Alvarez-Buylla A, Garcia-Verdugo JM, Tramontin AD (2001) A unified hypothesis on the lineage of neural stem cells. Nat Rev Neurosci 2:287-293.

Anchan RM, Reh TA (1995) Transforming growth factor-beta-3 is mitogenic for rat retinal progenitor cells in vitro. J Neurobiol 28:133-145.

Barami K, Iversen F, Furneaux H, Goldman SA (1995) Hu protein as an early marker of neuronal phenotypic differentiation by subependymal zone cells of the adult songbird forebrain. J Neurobiol 28:82-101.

Belecky-Adams T, Tomarev S, Li HS, Ploder L, McInnes RR, Sundin O, Adler R (1997) Pax-6, Prox 1, and Chx10 homeobox gene expression correlates with phenotypic fate of retinal precursor cells. Invest Ophthalmol Vis Sci 38:1293-1303.

Cao W, Li F, Steinberg RH, Lavail MM (2001) Development of normal and injury-induced gene expression of aFGF, bFGF, CNTF, BDNF, GFAP and IGF-I in the rat retina. Exp Eye Res 72:591-604.

Close JL, Fischer AJ, Roberts M, Reh TA (2000) Damage-induced expression of progenitor and neural cell markers in adult rodent Muller glia. Soc Neurosci Abstr 26:1603.

de la Rosa EJ, Bondy CA, Hernandez-Sanchez C, Wu X, Zhou J, Lopez-Carranza A, Scavo LM, de Pablo F (1994) Insulin and insulinlike growth factor system components: gene expression in the chicken retina from early neurogenesis until late development and their effects on neuroepithelial cells. Eur J Neurosci 6:1801-1810.

Doetsch F, Caille I, Lime DA, Garcia-Verdugo JM, Alvarez-Buylla A (1999) Subventricular zone astrocytes are neural stem cells in the adult mammalian brain. Cell 97:703-716. 
Ellis JH, Richards DE, Rogers JH (1991) Calretinin and calbindin in the retina of developing chick. Cell Tissue Res 264:197-208.

Fischer AJ, Reh TA (2000) Identification of a proliferating marginal zone of retinal progenitors in the postnatal chicken. Dev Biol 220:197-210.

Fischer AJ, Reh TA (2001a) Müller glia are a potential source of neural regeneration in the post-natal chick retina. Nat Neurosci 4:247-252.

Fischer AJ, Reh TA (2001b) Transdifferentiation of pigmented epithelial cells: a source of retinal stem cells? Dev Neurosci 23:268-276.

Fischer AJ, Seltner RLP, Poon J, Stell WK (1998) Immunocytochemical characterization of NMDA and QA-induced excitotoxicity in the retina of chicks. J Comp Neurol 393:1-15.

Fischer AJ, Morgan IG, Stell WK (1999) Colchicine induces excessive ocular growth and myopia in chicks. Vision Res 39:685-697.

Fischer AJ, Dierks BD, Reh TA (2002) Exogenous growth factors induce the production of ganglion cells at the retinal margin. Development 129:2283-2291.

Guillemot F, Cepko CL (1992) Retinal fate and ganglion cell differentiation are potentiated by acidic FGF in an in vitro assay of early retinal development. Development 114:743-754.

Hansson HA, Holmgren A, Norstedt G, Rozell B (1989) Changes in the distribution of insulin-like growth factor I, thioredoxin reductase and ribonucleotide reductase during development of the retina. Exp Eye Res 48:411-420.

Hartfuss E, Galli R, Heins N, Gotz M (2001) Characterization of CNS precursor subtypes and radial glia. Dev Biol 229:15-30.

Heins N, Malatesta P, Cecconi F, Nakafuku M, Tucker KL, Hack MA, Chapouton P, Barde Y-A, Götz M (2002) Glial cells generate neurons: the role of the transcription factor Pax6. Nat Neurosci 5:308-315.

Hernandez-Sanchez C, Lopez-Carranza A, Alarcon C, de la Rosa EJ, de Pablo F (1995) Autocrine/paracrine role of insulin-related growth factors in neurogenesis: local expression and effects on cells proliferation in retina. Proc Natl Acad Sci USA 92:9834-9838.

Jiang F, Frederick TJ, Wood TL (2001) IGF-I synergizes with FGF2 to stimulate oligodendrocyte progenitor entry into the cell cycle. Dev Biol 232:414-423.

Julian D, Ennis K, Korenbrot JI (1998) Birth and fate of proliferative cells in the inner nuclear layer of the mature fish retina. J Comp Neurol 394:271-282

Kostyk SK, D'Amore PA, Herman IM, Wagner JA (1994) Optic nerve injury alters basic fibroblast growth factor localization in the retina and optic tract. J Neurosci 14:1441-1449.

Kruchkova Y, Ben-Dror I, Herschkovitz A, David M, Yayon A, Vardimon L (2001) Basic fibroblast growth factor: a potential inhibitor of glutamine synthetase expression in injured neural tissue. J Neurochem 77:1641-1649.

Laywell ED, Rakic P, Kukekov VG, Holland EC, Steindler DA (2000) Identification of a multipotent astrocytic stem cell in the immature and adult mouse brain. Proc Natl Acad Sci USA 97:13883-13888.

Lendahl U, Zimmerman LB, McKay RD (1990) CNS stem cells express a new class of intermediate filament protein. Cell 60:585-595.

Levitt P, Rakic P (1980) Immunoperoxidase localization of glial fibrillary acidic protein in radial glial cells and astrocytes of the developing rhesus monkey brain. J Comp Neurol 193:815-840.

Lewis GP, Erickson PA, Guerin CJ, Anderson DJ, Fisher SK (1992) Basic fibroblast growth factor: a potential regulator of proliferation and intermediate filament expression in the retina. $\mathrm{J}$ Neurosci 12:3968-3978

Lillien L, Cepko C (1992) Control of proliferation in the retina: temporal changes in responsiveness to FGF and TGF $\alpha$. Development $115: 253-266$

Linser PJ, Schlosshauer B, Galileo DJ, Buzzi WR, Lewis RC (1997) Late proliferation of retinal Müller cell progenitors facilitates preferential targeting with retroviral vectors in vitro. Dev Genet 20:186-196.

Magavi SS, Leavitt BR, Macklis JD (2000) Induction of neurogenesis in the neocortex of adult mice. Nature 405:951-955.

Malatesta P, Hartfuss E, Gotz M (2000) Isolation of radial glial cells by fluorescent-activated cell sorting reveals a neuronal lineage. Development 127:5253-5263.

Marusich MF, Furneaux HM, Henion PD, Weston JA (1994) Hu neuronal proteins are expressed in proliferating neurogenic cells. J Neurobiol 25:143-155.

Mascarelli F, Tassin J, Courtois Y (1991) Effects of FGFs on adult bovine Müller cells: proliferation, binding and internalization. Growth Factors 4:81-95.

McCabe KL, Gunther EC, Reh TA (1999) The development of the pattern of retinal ganglion cells in the chick retina: mechanisms that control differentiation. Development 126:5713-5724.

Noctor SC, Flint AC, Weissman TA, Dammerman RS, Kriegstein AR (2001) Neurons derived from radial glial cells establish radial units in neocortex. Nature 409:714-720.

Noctor SC, Flint AC, Weissman TA, Wong WS, Clinton BK, Kriegstein AR (2002) Dividing precursor cells of the embryonic cortical ventricular zone have morphological and molecular characteristics of radial glia. J Neurosci 22:3161-3173.

Otteson DC, D'Costa AR, Hitchcock PF (2001) Putative stem cells and the lineage of rod photoreceptors in the mature retina of the goldfish. Dev Biol 232:62-76.

Patel A, McFarlane S (2000) Overexpression of FGF-2 alters cell fate specification in the developing retina of Xenopus laevis. Dev Biol 222:170-180.

Pittack C, Jones M, Reh TA (1991) Basic fibroblast growth factor induces retinal pigment epithelium to generate neural retina in vitro. Development 113:577-588.

Pittack C, Grunwald GB, Reh TA (1997) Fibroblast growth factors are necessary for neural retina but not pigmented epithelial differentiation in chick embryos. Development 124:805-816.

Politi LE, Rotstein NP, Salvador G, Giusto NM, Insua MF (2001) Insulin-like growth factor-I is a potential trophic factor for amacrine cells. J Neurochem 76:1199-1211.

Prada C, Puga J, Pérez-Méndez L, Lóper R, Ramírez G (1991) Spatial and temporal patterns of neurogenesis in the chick retina. Eur J Neurosci 3:559-569.

Rogers JH (1989) Two calcium-binding proteins mark many chick sensory neurons. Neuroscience 31:697-709.

Rogers JH, Khan M, Ellis JH (1989) Calretinin and other CaBPs in the nervous system. In: Calcium binding proteins in normal and transformed cells (Pochet R, Lawson DEM, Heizmann, CW, eds). New York: Plenum.

Sancho-Tello M, Valles S, Montoliu C, Renau-Piqueras J, Guerri C (1995) Developmental pattern of GFAP and vimentin expression in rat brain and in radial glial cultures. Glia 15:157-166.

Scharff C, Kirn JR, Grossman M, Macklis JD, Nottebohm F (2000) Targeted neuronal death affects neuronal replacement and vocal behavior in adult songbirds. Neuron 25:481-492.

Scherer J, Schnitzer J (1994) Growth factor effects on the proliferation of different retinal glial cells in vitro. Brain Res Dev Brain Res 80:209-221.

Seri B, Garcia-Verdugo JM, McEwen BS, Alvarez-Buylla A (2001) Astrocytes give rise to new neurons in the adult mammalian hippocampus. J Neurosci 21:7153-7160.

Shibata T, Yamada K, Watanabe M, Ikenaka K, Wada K, Tanaka K, Inoue Y (1997) Glutamate transporter GLAST is expressed in the radial glia-astrocyte lineage of developing mouse spinal cord. J Neurosci 17:9212-9219.

Valter K, Maslim J, Bowers F, Stone J (1998) Photoreceptor dystrophy in the RCS rat: roles of oxygen, debris, and bFGF. Invest Ophthalmol Vis Sci 39:2427-2442.

Walsh N, Valter K, Stone J (2001) Cellular and subcellular patterns of expression of bFGF and CNTF in the normal and light-stressed adult rat retina. Exp Eye Res 72:495-501

Wen S, Song Y, Cheng T, Matthes MT, Tasumura D, LaVail MM, Steinberg RH (1995) Injury-induced upregulation of bFGF and CNTF mRNAs in the rat retina. J Neurosci 15:7377-7385. 